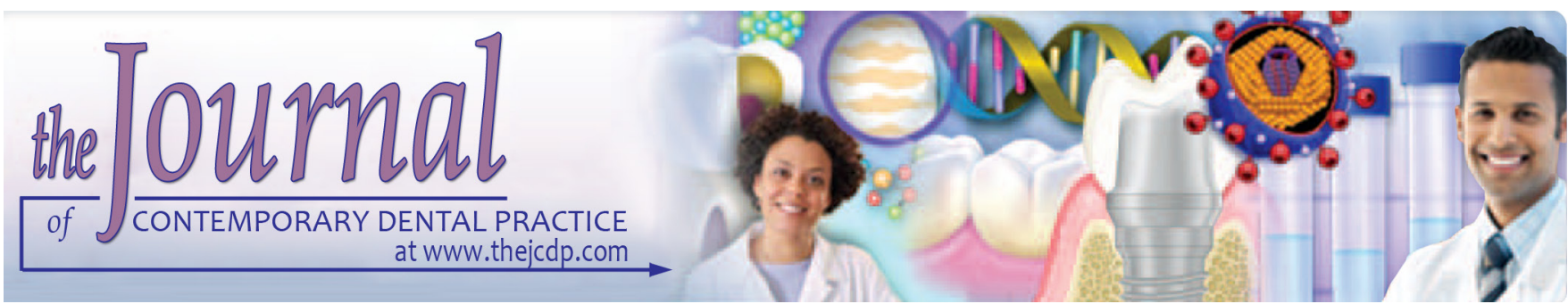

\title{
Dental Arch Dimensions and Form in a Sudanese Sample
}

\author{
${ }^{1}$ Hashim K Saeed, ${ }^{2}$ Adil O Mageet
}

\begin{abstract}
The aim of this study is to determine the dental arch dimensions (width and length) and form in a group of a Sudanese sample population.
\end{abstract}

Background: The size and shape of dental arches have significant implication in orthodontic diagnosis and treatment planning as it affects the space available, dental esthetics and stability of the occlusion.

Materials and methods: This study is a biometric analysis of dental casts of 50 adult Sudanese dental students $(20$ males, 30 females) aged between 19 to 22 years with normal occlusion. The study was conducted at the orthodontic clinics, Faculty of Dentistry, University of Khartoum. Each student was interviewed and written consent was given. The inclusion criteria were: complete permanent dentition fully erupted to the occlusal plane, no proximal caries or restorations, no attrition or dental anomalies, no extractions, no previous or ongoing orthodontic treatment and no fractures or jaw surgeries. Paired-test, ANOVA test, and Pearson's correlation were used for statistical analysis with a $p$-value set at 0.05 .

Results: The result showed normal occlusion is higher in males than in females. Upper arch dimensions (width and length) found to be higher in males than females, inter canine width (ICW), males 36 , and females 34.45 ; interpremolar width (IPmW) males 48.08, females 47.58; inter-molar width (IMW) males 53.04, females 52.4; the length for males 37.98 and for females was 37.09. Comparison of Lower arch dimensions between males and females showed ICW (27.08 and 26.86); IPmW (40.97 and 39.67); IMW (45.61 and 45.69); depth was (33.91 and 33.91) consequently. The ovoid-shaped arch form was more common in both genders.

${ }^{1}$ Orthodontic Department, Faculty of Dentistry, University of Khartoum, Khartoum, Sudan

${ }^{2}$ Department of Orthodontics, Hamdan Bin Mohammed College of Dental Medicine, Mohammed Bin Rashid University, Dubai, UAE.

Corresponding Author: Adil O Mageet, Department of Orthodontics, Hamdan Bin Mohammed College of Dental Medicine, Mohammed Bin Rashid University, Dubai, UAE, Phone: +971 553378730, +249 912546907, e-mail: adil. mageet@MBRU.ac.ae, amageet2000@yahoo.co.uk
Conclusion: Length dimension showed the highest value with square arch form. The width dimensions increase with little change in the inter-canine region but appreciably more in the distal part of the arch. Men have a more massive arch form than females. The ovoid arch form dominates in the Sudanese population.

Clinical significance: Knowledge of arch dimensions that are associated with normal occlusion is helpful in determining treatment goals and proper diagnosis and treatment plan by choosing the right arch form for each race.

Keywords: Arch form, Arch length, Arch width

How to cite this article: Saeed HK, Mageet AO. Dental Arch Dimensions and Form in a Sudanese Sample. The Journal of Contemporary Dental Practice, October 2018;19(10):1235-1241.

Source of support: Nil

Conflict of interest: None

\section{BACKGROUND}

It is essential to maintain dental arch dimensions and arch form during orthodontic treatment. ${ }^{1}$ Dental arch width, length, and form are important values for the diagnosis, treatment planning prognosis and stability of the orthodontic results which concerns all Orthodontic age group patients. ${ }^{2}$

Different ethnic groups and populations display variable dental arch measurements and characteristics. ${ }^{2}$ It is well-known that dental arch dimensions continue changing throughout growth and development, but during adulthood, the chances decrease. ${ }^{1}$ This explains why many researchers were interested in investigating the changes in dental arch dimensions during each stage of growth and development. ${ }^{2-8}$ It is well noted in the literature that using preformed archwires for orthodontic patients, regardless of their arch form, will lead to post-treatment relapse. ${ }^{9}$ Accordingly, there have to shift from using preformed archwires routinely for all patients to selecting specific archwires for individual patients, depending on his or her arch form and malocclusion adaptability. Several researchers had been trying 
to classify the dental arch forms. It is accepted that the dental arch is shaped and confined by the supporting bone configurations, and it is affected by the eruption of teeth and the surrounding muscular forces. ${ }^{6}$

Dental Arch width is the dimension experiencing the largest changes with age. ${ }^{10}$ Inter-canine width changes the least, with the average increase over time being progressively larger through the premolar segment and into the molar region. The least change occurs for the mandibular inter-canine width, which shows no statistically significant difference from its starting point. ${ }^{10}$

A trend towards greater acceptance of arch development and expansion has followed advances in orthodontic appliances and archwires..$^{11}$ Longitudinal studies have highlighted the potential for relapse related to the expansion of the transverse dimension, particularly in the mandibular inter-canine width. ${ }^{11}$

A study of gender differences in arch widths among Class I normal occlusions of Saudi subjects showed males to have significantly higher values for maxillary and mandibular intermolar and intercanine width than females. ${ }^{12}$

Tooth widths and arch dimensions are considered significant information by anthropologists, quite apart from their value to orthodontists in understanding dimensional arch criteria and orthodontic archwire selection. ${ }^{13,14}$

Dental arch width increases during both the phases of mixed and permanent dentitions, leading to information about the subject's age and body being factors expected to refine arch width estimates..$^{15}$ A study of 65 healthy Caucasian children followed from birth to over 25 years of age, including those with malocclusions, found a progressive increase in arch width, especially in males. ${ }^{16,17}$

Dental arch width continues to increase to a lesser extent in the third and fourth decades, but this is associated with arch length shortening, male arches grow wider than female arches. ${ }^{11}$ The lower inter-canine width increases significantly in the changeover dentition but does not increase in the permanent dentition after 12 years of age. The upper and lower inter-molar width increases spontaneously to a considerable extent between 7 and 18 years, especially in males. Furthermore, little change in arch width occurs in the premolar region after the age of twelve. $^{18}$

Dental Arch length is the average perpendicular distance from the central incisors to the molar cross-arch dimension, expressed in millimeters. ${ }^{19}$ Comparison between Afro-Americans and Caucasian Americans revealed Afro-Americans to have highly significant larger mean arch widths and lengths than Caucasians. Additionally, with the difference in arch lengths differing relatively more between ethnic groups. ${ }^{20}$ However, changes in arch width are not always accompanied by changes in arch length; there is a tendency toward a decrease in arch length in the third and fourth decades of life. ${ }^{18}$

Dental Arch form defined as the position and relationship the teeth have with each other and should always be considered in three dimensions. ${ }^{21}$ Adult male subjects possess significantly larger arches than adult female subjects. ${ }^{17}$ However, no gender differences in shape have been found in the comparison of homologous teeth. ${ }^{22}$

In general, it was found that the dimensions of the dental arches increased upto 9 years of age in the incisor region, and up to 11 to 13 years in the other regions of the jaws; there is little change after that ${ }^{16}$ It is essential to maintain dental arch dimensions during orthodontic therapy; all possible dental arch forms must be evaluated. ${ }^{23}$

A lack of stability in the arch form in subjects with normal occlusions during the transition from adolescence into adulthood further questions the possibility of achieving stability post orthodontically. ${ }^{24}$ No significant differences in arch forms distribution were seen between male and female subjects. However, the dental arches of the females exhibited smaller dimensions. ${ }^{25}$

Different methods are used to measure arch dimensions; study cast analysis is a three-dimensional assessment of the maxillary and mandibular dental arches, and the maximal intercuspation relationship is one of the essential tools of diagnosis and treatment planning. ${ }^{26}$

Many researchers have been carried out to document dental arch dimensions and forms in several populations, but no data come from the Sudanese people. Therefore this study aimed to determine the arch dimensions and arch forms in a group of a Sudanese Sample population with normal occlusion.

\section{MATERIALS AND METHODS}

This study is a cross-sectional descriptive study conducted at the Orthodontic Clinics, Faculty of Dentistry, University of Khartoum.

A total of 50 dental casts of students attending the Faculty of Dentistry, University of Khartoum, aged between 19 to 22 years, with normal occlusion were selected.

The inclusion criteria were: (a) Sound pre-treatment orthodontic models of adult patients; (b) Full permanent dentition in both arches excluding third molars; (c) Class I, Class II, and Class III malocclusion.

The exclusion criteria were: (a) Casts from children with mixed or primary dentition; (b) Hypodontia, supernumeraries, dental anomalies, posterior crossbite, retained deciduous teeth, severe transverse arch discrepancies and severe crowding. 
Measurements from the casts were taken using a digital caliper (G and H Wire Company, 2165 Earlywood Drive, Franklin, IN 46131 USA).

\section{Width Measurement}

The intercanine width between the cusp tips for both maxillary and mandibular arches was recorded. The Interpremolar width was recorded for both arches from the mesio-occlusal pit of the first premolars.

The Inter-molar width recorded for both arches from the mesio occlusal pits of the first permanent molars (Fig. 1).

\section{Length Measurement}

A perpendicular drawn from the inter-incisal point to a line drawn from the distal surface of the maxillary and mandibular permanent first molars (Fig. 2).

\section{Arch Form}

A modified arch forms referring to the Ricketts pantamorphic arch form templates, ovoid, tapered (V-shaped), and square (U-shaped) forms (Fig. 3).

The above parameters were measured on the selected dental cast models in random order by the same examiner.
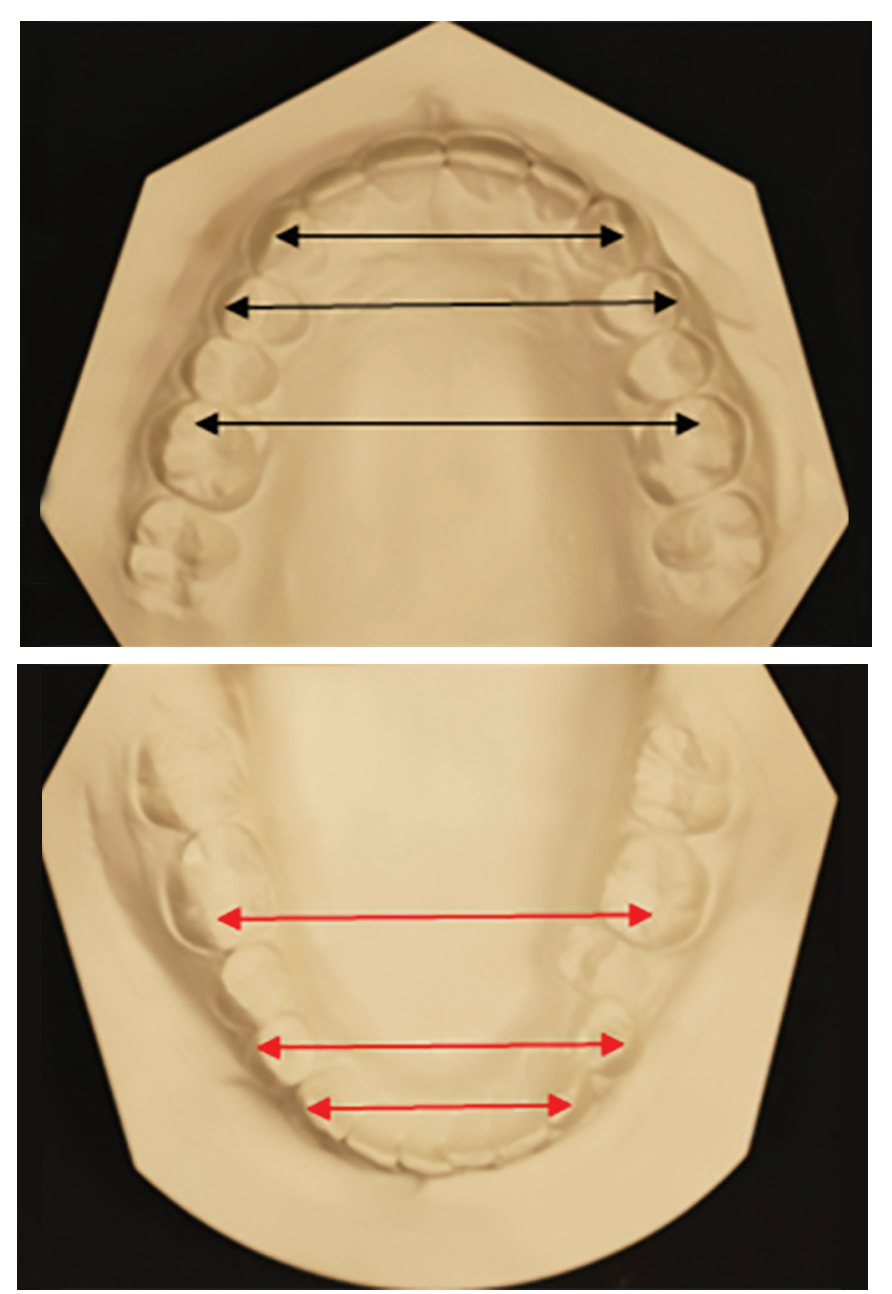

Fig. 1: Width measurement
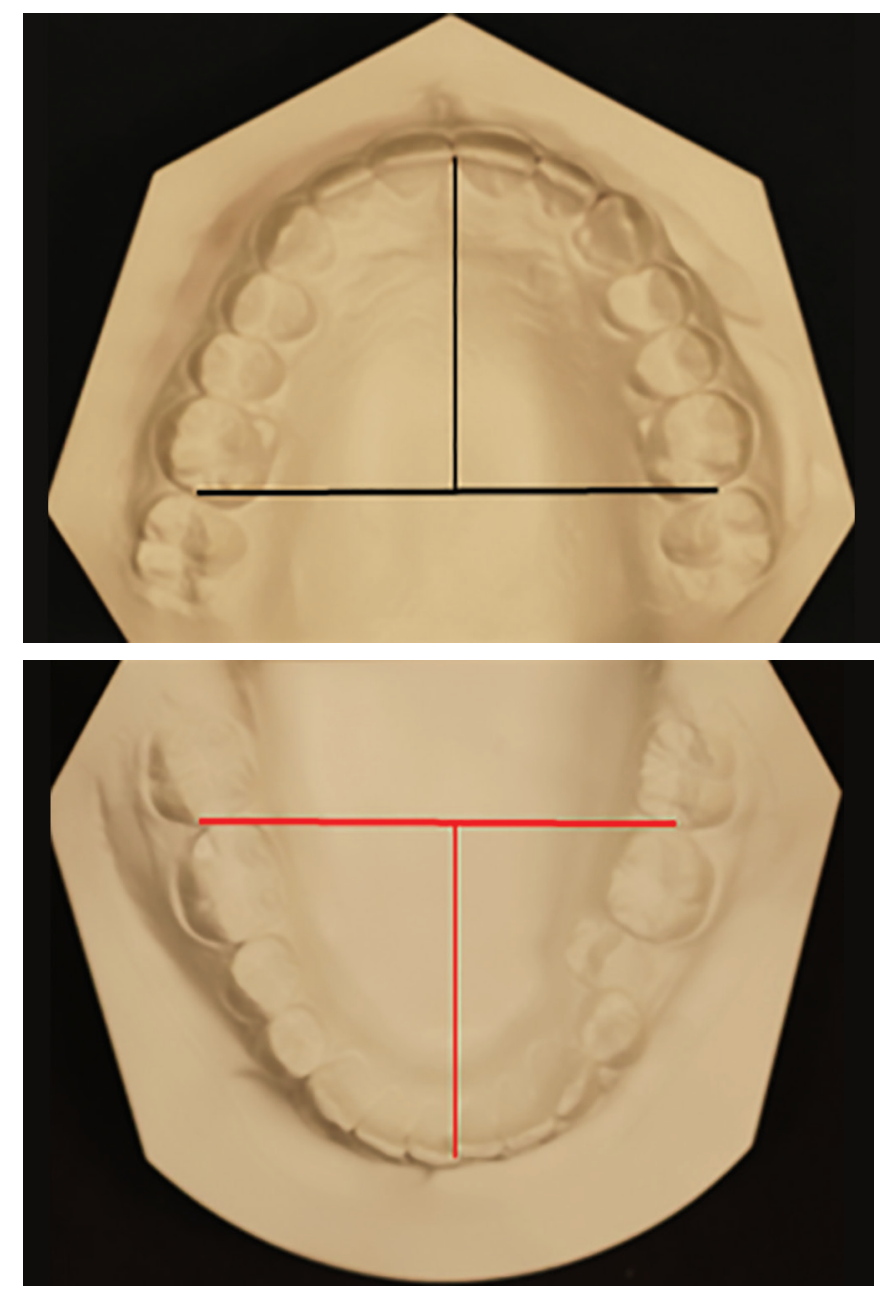

Fig. 2: Length measurement

An intra-examiner calibration was also conducted. Data were analyzed using SPSS version 22.0 (Chicago, Illinois, USA). Simple descriptive statistics were used to define the characteristics of the study variables through a form of counts and percentages for the categorical and nominal variables; mean and standard deviations presented continuous variables.

\section{Data Analysis}

The data was collected and analyzed using SPSS version 22.0 (Chicago, Illinois, USA) by applying the $t$-test. The level of significance was set at $\mathrm{p}=0.05$

\section{Reliability of Measurement}

The measurement error was assessed by repeating the measurement of 15 randomly selected casts by the same investigator after two weeks period.

The initial and repeated measurements were compared using Dahlbergs' formula.

$$
\mathrm{ME}=\sqrt{\frac{s d^{2}}{2 n}}
$$



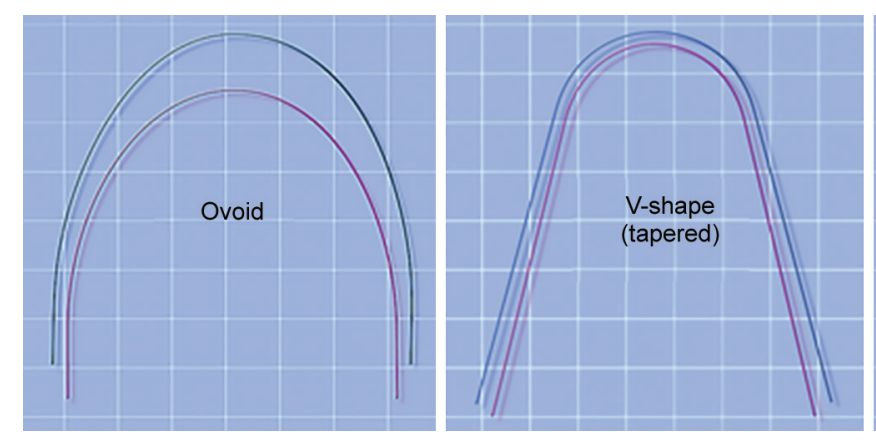

Fig. 3: Arch forms

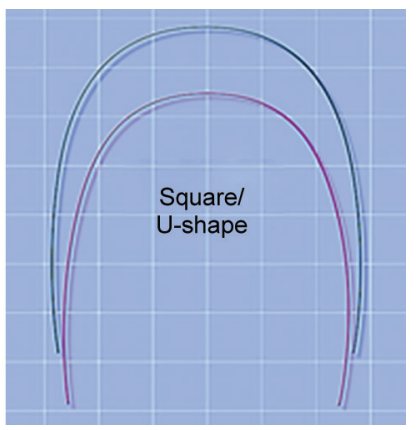

$\mathrm{ME}=$ method error.

$\mathrm{n}=$ repeated reading.

$\mathrm{d}=$ different between first and second reading.

\section{RESULTS}

The statistics regarding the width and length shows the upper arch to be wider and longer than the lower arch (Graph 1 and Table 1). In relation to the gender, the upper arch also showed the same results (Graph 2). The ovoid arch form showed the most repeated shape, followed by the square and the least is the V-shaped arch (Graph 3 and Table 2).

The Pearson correlation and the t-test have shown significant results in relation to the inter-canine width, inter-premolar width, and inter-molar width.

\section{DISCUSSION}

The sample size for this survey was 50; this sample cannot be considered representative as it was recruited in one place, the University of Khartoum. The results give a good idea of the arch dimensions and forms in the Sudanese population.

The dimensions recorded for upper and lower dental arches were: for the inter-canine width upper and lower $28.5 \pm 2.3,22.4 \pm 2.3$, inter-premolar width upper and lower $41.9 \pm 3.1,35.1 \pm 3.1$, inter-molar width upper and lower $46.4 \pm 3.3,41.1 \pm 2.8$, and finally, the Length of upper and lower arches was $44.8 \pm 2.8,41.1 \pm 4.7$ respectively.

Figure 4 shows that the general results obtained agree with the idea that the upper arch length is larger than the lower arch length, something in accord with the Swedish

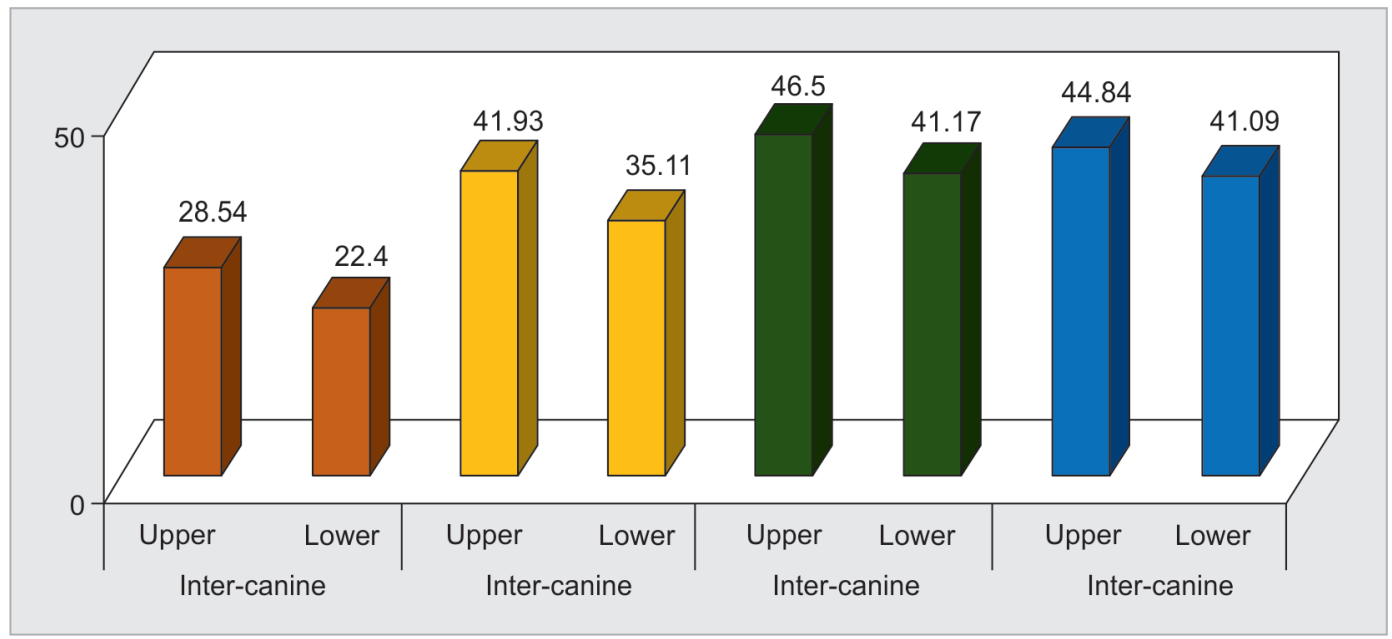

Graph 1: Statistics according to arch width and length

Table 1: Pearson correlation

\begin{tabular}{|c|c|c|c|}
\hline & & Correlation & Sig. \\
\hline Intercanine width & Upper/ lower & 0.329 & 0.020 \\
\hline Interpremolar width upper & Upper/ lower & 0.545 & 0.000 \\
\hline Intermolar width upper & Upper/ lower & 0.416 & 0.003 \\
\hline Arch length upper & Upper/ lower & 0.406 & 0.003 \\
\hline
\end{tabular}




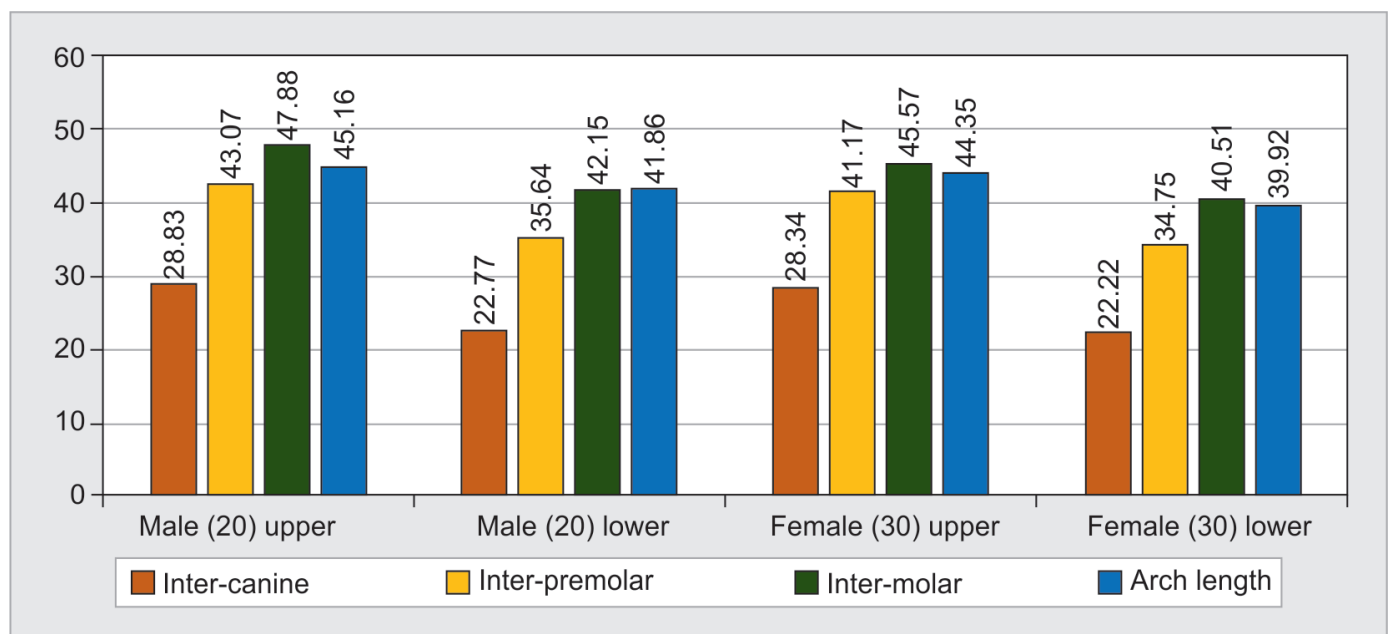

Graph 2: Arch width and length according to gender

Table 2 : Paired $t$-test

\begin{tabular}{|c|c|c|c|c|c|c|c|}
\hline \multirow[b]{3}{*}{ Variables } & \multicolumn{7}{|c|}{ Paired Differences } \\
\hline & \multirow[b]{2}{*}{ Mean (SD) } & \multirow{2}{*}{$\begin{array}{l}\text { Std. Error } \\
\text { of the } \\
\text { Mean }\end{array}$} & \multicolumn{2}{|c|}{$\begin{array}{l}95 \% \text { Confidence Inter- } \\
\text { val of the Difference }\end{array}$} & \multirow[b]{2}{*}{$t$} & \multirow[b]{2}{*}{$d f$} & \multirow{2}{*}{$\begin{array}{l}\text { Sig. } \\
\text { (2-tailed) }\end{array}$} \\
\hline & & & Upper & Lower & & & \\
\hline Inter-canine width upper/lower & $6.10(2.73)$ & 0.39 & 5.32218 & 6.87682 & 15.780 & 49 & $0.000^{* * *}$ \\
\hline Inter-premolar width upper/lower & $6.82(2.97)$ & 0.42 & 5.97956 & 7.66764 & 6.246 & 49 & $0.000^{* \star *}$ \\
\hline Inter-molar width upper/lower & $5.33(3.37)$ & 0.48 & 4.37262 & 6.28658 & 11.192 & 49 & $0.000^{* * *}$ \\
\hline Upper arch length/lower arch length & $3.75(4.47)$ & 0.63 & 2.48457 & 5.02303 & 5.943 & 49 & $0.000^{* * *}$ \\
\hline
\end{tabular}

study, ${ }^{18}$ the Italian study, ${ }^{27}$ the British study ${ }^{28}$ and the German study. ${ }^{29}$

No significant changes were seen, apart from the fact that the gender balance and the methodology used in each study varied considerably.

The results obtained in the comparison between genders were more noticeable in the inter-molar width, with mean values of $37.9 \pm 2.5$ in females and $45.6 \pm 3.5$ in males regarding the upper arch, with a significance of 0.015; but for the inter-canine width and inter-premolar width of upper and lower arches, the results show a decrease greater in females than in males, a finding in conflict with the study conducted by Sillman. ${ }^{17}$

Because of the divergent shapes of the dental arches anteroposteriorly, movements of a whole arch require modification to the arch width to accommodate the (posing) arch. This is most frequently seen in the distal movement of the upper arch or forward movement of the lower arch; the upper arch is expanded in either case to accommodate the lower arch. It is possible that some of the upper arch expansion achieved could also be maintained in the lower arch, ${ }^{20}$ but in another study of adult

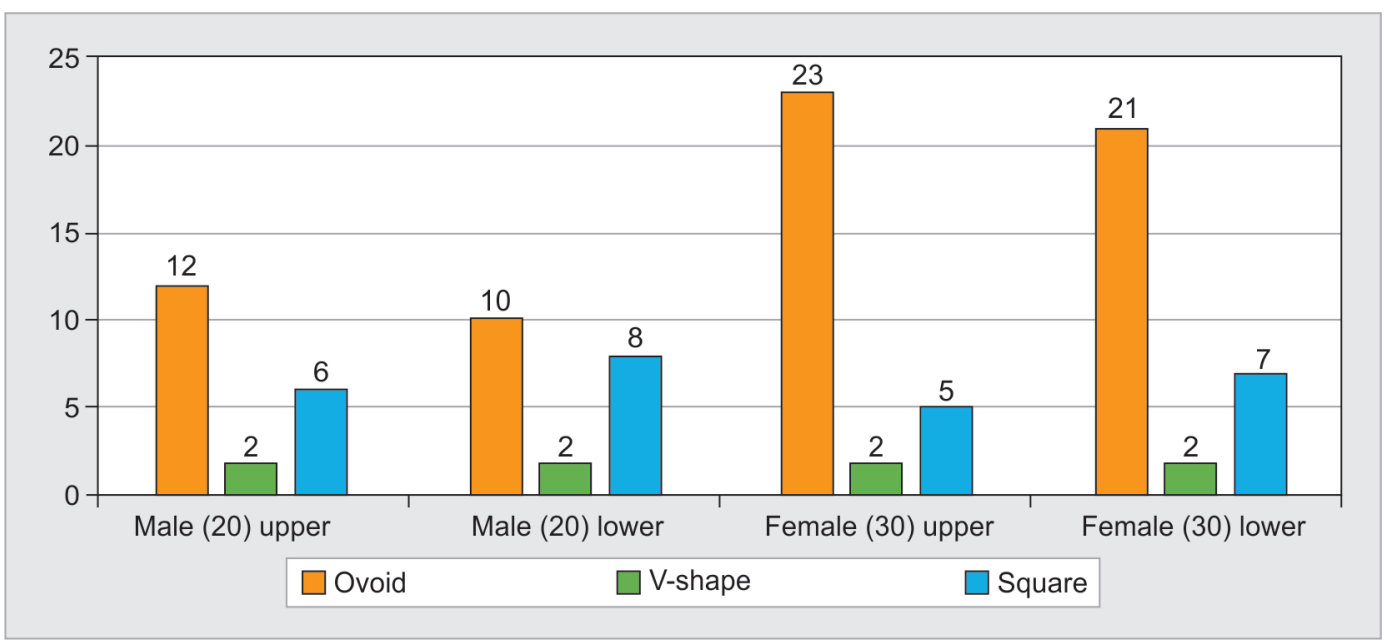

Graph 3: Arch shape according to gender and its frequency 
males, a significant increase in arch width in comparison with females was shown, and this is the degree of sexual dimorphism that changes little during adulthood. ${ }^{19}$ The explanation may lie in the fact that the earlier date back some years, and the techniques available to assess the arch width have changed to computerized methods of measurement.

When comparing dimensions of upper and lower arches length, the correlation showed 0.329 with a significance of 0.020 for inter-canine width. The inter-premolar width for upper and lower arches showed a correlation of 0.545 , and a high level of significance of 0.000 . In inter-molar width, the correlation was 0.0416 with a high significance of 0.003 , whereas, in arch length, the upper and lower correlation showed 0.0406 with a significance of 0.003 as shown in Table 2.

The arch forms studied were U-shaped, V-shaped and Ovoid shaped, with the later showing the highest prevalence. A recent Saudi study found the most prevalent arch form to be the narrow tapered followed by the narrow ovoid. ${ }^{14}$ This is difference could be related to the wider African race (Afro-Arab) when compared to the Saudi sample.

When comparing upper arch forms, the Ovoid shape showed lower prevalence in males than females, $12(60 \%), 23(76.7 \%)$. Regarding the U-shaped form, no differences were found since both were observed in two subjects; the V-shaped form showed little variations, with an observed figure of four occurrences for each gender. When comparing the lower arch, females showed to have a higher frequency 21 (70\%) regarding the Ovoid shape, when compared to males $10(50 \%)$. The occurrence of the V-shaped form showed no difference, with an occurrence of two. The U-shaped form also showed little variation with a value of five.

\section{CONCLUSION}

The sample size is of 50 student does not permit the establishment of norms, but gives a general guideline for arch dimensions and form.

The dimensions recorded showed that arch width in males is greater than females, particularly for the inter-molar width, $(37.9 \pm 2.5$ in females and $45.6 \pm 3.6$ in males) for the upper arch. The general results attained are consistent with the fact that the upper arch is larger than the lower arch.

It could be concluded that that upper and lower arches width in the comparison between males and females shows men to have a larger arch form.

The length dimensions of the upper and lower arches showed the highest value in the square form. An upper/ lower arch width comparison showed males to have a more massive arch form. The arch width increases with little change in the canine region but appreciably more in the distal part of each arch.

The ovoid arch forms dominate in the Sudanese sample.

\section{RECOMMENDATIONS}

We recommend that the selection of archwires for orthodontic treatments to be ovoid, as this is the form most prevalent in our sample.

We also recommend an expansion of this study to survey larger samples to reflect the Sudanese population as a whole and to set a norm for dental arch width, length, and form.

\section{CLINICAL SIGNIFICANCE}

Knowledge of arch dimensions that are associated with normal occlusion is helpful in determining treatment goals and proper diagnosis and treatment plan by choosing the right arch form for each race.

\section{REFERENCES}

1. Trivino T, Siqueira DF, Scanavini MA. A new concept of mandibular dental arch forms with normal occlusion. Am J Orthod Dentofacial Orthop 2008;133:15-22.

2. Carter GA, McNamara JA. Longitudinal dental arch changes in adults. Am J Orthod Dentofacial Orthop 1998; 114:88-99.

3. Defraia E, Baroni G, Marinelli A. Dental arch dimensions in the mixed dentition: a study of Italian children born in the 1950s and the 1990s. Angle Orthod 2006;76:446-451.

4. Barrow GV, White JR. Developmental changes of the maxillary and mandibular dental arches. The Angle Orthod 1952;22:41-46.

5. Bishara SE, Ortho D, Jakobsen JR, Treder J, Nowak A. Arch width changes from 6 weeks to 45 years of age. Am J Orthod Dentofacial Orthop 1997;111:401-409.

6. Lundström A. Changes in crowding and spacing of the teeth with age. The Dental practitioner and Dental Record 1969;19:218-224.

7. Moorrees CF. The dentition of the growing child: a longitudinal study of dental development between 3 and 18 years of age. Cambridge (USA): Harvard University Press; 1959. www.smj.org.sa Saudi Med J 2018; 39(1):91.

8. Sillman JH. Dimensional changes of the dental arches: longitudinal study from birth to 25 years. Am J Orthod 1964;50:824-842.

9. Engel GA. Preformed arch wires: reliability of fit. Am J Orthod 1979;76:497-504.

10. Knox J, Jones M, and Durning P. An ideal preformed archwire? Br J Orthod 1993;20:65-70.

11. Natalia Alvaran SIR, and Peter H. Buschang. maxillary and mandibular arch widths of Colombians. Am J Orthod Dentofacial Orthop 2009;135:649-56.

12. Yun YK, Kim SH, Mo SS, Cha KS, Kim JG, Tae KC. Mandibular clinical arch forms in Koreans with normal occlusions. Korean J Orthod 2004; 34: 481-87. 
13. Al-Tamimi T. S. An odontometric study of tooth size and arch dimensions in a Saudi sample with normal occlusion (MSc Thesis), Faculty of Dentistry, King Saud University, 2000.

14. Omar H, Alhajrasi M, Felemban N, Hassan A. Dental arch dimensions, form and tooth size ratio among a Saudi Sample.Saudi Med J. 2018;39(1):86-91.

15. Angle EH. Growth during adult life. Proc Am Phil Soc 1936;76:847-97.

16. Knott VB. Longitudinal study of dental arch width at four stages of dentition. Angle orthod 1972;42:387-395.

17. Benjamin G, Burris A, Edward F, Harris EF. Maxillary Arch Size Shape in American Blacks and Whites, Angle Orthod 2000;70:297-302.

18. Harris EF. A longitudinal study of arch size and form in untreated adults. Am J Orthod Dentofacial Orthop 1997;111:419-427.

19. Hashim HA, Al-Ghamdi SAF. Tooth Width and Arch Dimensions in Normal and Malocclusion Samples: An Odontometric Study. J Contemp Dent Pract 2005;6: 36-51.
20. Williams PN. Determining the shape of the normal arch. Dental Cosmos 1917;59:695-708.

21. Robert TL. Arch width and form. Am J Orthod Dentofacial Orthop 1999;1:305-313.

22. Foster TD. A cross-sectional study into age changes of the human dental arch. Archives of Oral Biology 1969;14:71-86.

23. Henrikson JPM, Thilander B. Long-term stability of dental arch form in normal occlusion from 13 to 31 years of age. Eur J Orthod 2001;23:51-61.

24. Ferario VF. Human dental arch shape evaluated by Euclidan distance matrix analysis. Am J of Physical Anathropology 1993; 90:445-453.

25. Mutinelli S, Cozzani M, Manfredi M, Siciliani G. Dental arch analysis system. Orthod 2004;5(2):200-211.

26. Fleming PS, Dibiase AT, Lee RT. Arch form and dimensional changes in orthodontics. Orthod 2008a;9:5864.

27. Sampson PD. Dental arch shape: Astatistical analysis using conic sections. AJO 1981;79:535-548.

28. Rudge SJ. Dental arch analysis: arch form, a review of the literature. Eur J Orthod 1981; 3: 279-384. 